\title{
The Formation and Evolution of the Classical View of Ancient Literature
}

\author{
Mingfeng LV \\ Xi'an Peihua University; Xi'an 710125 China
}

\begin{abstract}
Keywords: ancient literature; the classical view; new classic.
\end{abstract}
\begin{abstract}
This paper studies the key problems in the formation of the ancient Chinese literary classic view, such as the significant factual questions: the evolution from traditional Buddhist scriptures to independent literature, the historical backtracking from classic to anti-classic. The process of studying these problems reflects the fluctuation and controversy in the formation of classical view of ancient literature. Therefore, to study the development of Chinese classical literature movement and commentary, we usually take the classical view as the entry point.
\end{abstract}

\section{Introduction}

There are many different types of classical definitions. Western romanticism literature classic is different from the classical literature of traditional Chinese classical in priorities and expounding of the key problem, but there is no denying that classic refers to a kind of works with authority and canonical meaning. The ancient Chinese literature also has same views with the Western that the study of literary classics is based on a series of classical ideas. Based on this problem, this paper makes a simple analysis and definition of classical view.

\section{The Initialization of Class Works and the Formation of Classical Theory}

The influential literary schools and literary critics in ancient China have had similar expressions about classical problems. Xunzi, the first litterateur who made a systematic exposition of classic problems through approve and promote of the theory of Confucius, said in his article $<$ To Encourage Learning>:" The order of study is to begin with reading the classics such as <collection of ancient texts

$>,<$ the book of songs $>$ and so on, and end with $<$ The Book of Rites $>$ ". It reflects the important role of classics for the study and reference of the world. Literature in Wei, Jin, southern and northern dynasties and the eastern Han also constantly expressed their opinions about the importance of classic. For example, Wang Chong said in $<$ Lun heng $>$. "The society likes precious ancient times but not modern, they think modern books are inferior to ancient books. In fact, the ancient and modern are the same, t.......only precious ancient books mean that the ancients are wiser than the present." The literature and the writers of this period were influenced by the Confucianism of the pre-Qin period, which kept a good theoretical and classical view of the transitional problems of the Confucian spirit and practice in the pre-Qin period. They believe that learning classics will help the study or writing, but it is also clear that the concept of "book" in this period is not a literary work, but they have a positive effect for the birth of literary classics.

In addition, we can learn the formation process of theoretical classical view through the definition of classic. Xunzi had written in his article, the classic is a record of the thought of the sage. To understand the thoughts and life of the saints, we need to learn the classics. Xunzi clearly expresses his admiration for the classics and represents the formation of Confucian classics to a certain extent.

Later, Yangxiong also expressed his approval and praise for the writings and speeches of sage." To study the law of the universe without read $<$ the five classics $>$ is like to swim across a river without a boat" In his point of view, the role of classics is not only an authoritative example, its own literariness also has a certain influence on the study of later generations. The literariness of classic works is reflected in <Xunzi>. There are a lot of rhetorical devices in <Xunzi $>$, such as the parallel construction, metaphor, rhetorical question and truth. The use of the parallel construction can 
enhance the momentum of the article and make the article more convincing. For example, $<$ Xunzi-Feishierzi $>$ : "To believe in something that is believable is wise;

To doubt something suspicious is also wise. To respect the virtuous is kindness.

To despise the villains is also [7] [8] [9] kindness, to speak properly is a kind of wise; to be silent is also a kind of wise." In this paragraph, three sentences are used, and the sentence pattern is coherent and orderly. The form of the two or three words makes the overall reading experience of the article more relaxed and more expressive. The use of figurative sentences is also a feature of $<$ Xunzi $>$. For example, in the music theory, the metaphor of "voice": "So the sound of music is as clear as the sky, as broad as the earth and as distinct as the four seasons." In this description, Xunzi has strengthened the understanding of this music form by comparing the music and the human voice to the heaven and the earth. This description highlighted the relation between metaphor ontology and metaphor body, and Xunzi's understanding of music is highlighted by the way of metaphor. Compared with the general rhetorical devices, metaphor can better convey the author's understanding and perception of the things to be described.

Through the above analysis, it is basically clear that, In the period of pre-Qin and Han dynasties, the classics mainly referred to the Confucian classics, and there was little discussion on the literary classics. It could be said that this period had not yet formed an independent literary classic concept. At this time, the classical judgment is mainly based on its influence and value characteristics, and it has less consideration on literariness. As a synonym for this stage, the works of thought are enlightening to the formation of later literary classics during actual development.

\section{The Prosperity of Literary Works Inherits the Theory of Classics and Classical Literature Has Been Formed.}

The classic literature was formed during the period of the Wei, Jin and southern and northern dynasties. There were many literary works in this period, and the literary criticism was developing towards the trend of liberal arts. In this period, classical literature began to attach importance to the political function and aesthetic function of literature. Through reviewing the works of specific literary writers, it formed the classical view of literary creation. During this period, a great number of classics were produced, such as Liu Xie's "Wen Xin Diao Long", which is a work that sums up the thought of Confucianism in the pre-Qin period and develop it as political service. Zhong Rong's $<$ comments of poems $>$ is another masterpiece of the literary theory of the southern dynasty. This book is of great significance as the first treatise on poetics in the history of Chinese literature. This work collects and systematically reviews the works of 122 poets in the Han and Wei dynasties, and makes a systematic and accurate exposition of the creation method and theoretical source of their works. This work breaks through the shackles of ancient literary writing and sets up its own literary standard in the expression of the classic summary and evaluation. For example, he praised Cao Zhi for his "integrity and good writing," this thought achieved the unity of thought and writing. This breakthrough the phenomenon that

the theory of literature writing under the guidance of traditional Confucian thought has little practical application.

During the Wei, Jin and southern and northern dynasties, Liu Xie believed that the classics were not only an example for the later generations, but also provided a favorable reference standard for later literature works in the ideological and artistic system. The classic works of this period not only have the value of inheriting the literature thought, but also have a broader concern on the practical aspect such as Ethics, politics, economy, law, society and so on. The writing and literary criticism of literary works become another way to judge classic works. For example, Zhong Rong's comments of poems is such a classic work. As the first treatise on poetics in the history of Chinese literature, it sets up a classic paradigm in the wide range of comments and the various aspects of the works. He commented on 122 poets in the Han and Wei dynasties. According to the expression of their works, their ideological character and literary characteristics, these poets are divided into three categories. The purpose of his writing is to tease out the process of poetic development, to clarify the evolution of the genre, and to provide good theoretical guidance for contemporary poets. This distinction opens 
new age of literary classics, which extends the definition of classics from works creation to literary criticism which have the value to study and take as an example. For example, Zhong Rong, through his analysis of the works of poets in the southern dynasty, thinks that Cao Zhi, Xie Lingyun and other people are poets in the first team. This reflects the continuous development of the classical view of literary creation. At the same time, what is more prominent is that he uses literary criticism to comment on classical literature. For example, he praised Cao Zhi that "a poet with high level of thoughts and writing skills that could be an example crossing ages". His comments have considered both the thoughts of the poet and the writing skills of literature and put Cao Zhi as the representative of the highest achievement of the classical poets. [10]

\section{The Literary Retro Movement in the Sui and Tang Dynasties Helped to Promote the Formation of the Classical View of Ancient Literature.}

From the sui and tang dynasties to the song dynasty, it was an important period for the development of Chinese classical literature. During the period, several important literary retro sports overturned people's views on classical literature. People have a deeper understanding of the classics and more conscientiousness, which makes the literary classic position more consolidated. The creation of poetry and prose has evolved over hundreds of years. Chen Ziang summarized the poetic style of the Jin period, the Han Wei dynasties and the northern and southern dynasties. He criticized the prevailing literary style that speak nothing with beautiful words in the early tang dynasty. He believes that the process of reconstructing the classic is the future of literary creation. This thought makes poetry creation in the early tang dynasty become the contradictory node of restoring ancient ways and innovation. The classical idea of poetry creation in this period gradually influenced tang poetry creation in the middle and late tang dynasty. After the song dynasty, the large-scale retro movement made the prose writers write the classic prose. The famous representatives include Meiyaochen, Ouyangxiu, Zeng gong, Wanganshi and others. In the southern song dynasty was the completion period of the poetry revival movement. They promoted the study of classical poetry, such as the book of songs and li SAO, and revived the classical style.

In the late tang and early song dynasty, Chen Ziang was the first to express his dissatisfaction with the fading and classical decline of the past poetry. In his work, he called for the promotion of elegance and maintain the elegance of the book of songs, At the same time, the author thinks that poetry creation should be inherited and carried forward by study the works in in the Han and Wei dynasties. He is opposed to the flashy and discomfiting poems that have prevailed since the beginning of the tang dynasty, and he emphasize the classic works in a classic way. After Chen Ziang, the second vintage movement began in the middle tang period, and the main area for the study was prose. They fight against parallel prose of the six dynasties which abandoned the creation method of classical prose, and the one-sidedly pursuit the literary beauty with no attention to the expression of literary thought. They think it is wrong to think that this flashy article is a new kind of aesthetic. Parallel prose has a bad influence, because it does not pay attention to the thought, to cater to the social atmosphere of the time. The ancient prose movement represented by Han Yu and Liu Zongyuan opposed the parallel prose and advocated the literary beauty and ideological value of the prose in the Qin and Han dynasties. They said in "the answer to li ling": "When I began to study the article, I did not read the book that were not wrote during the pre-Qin and the Han dynasty", and they praised Zhuangzi, Xunzi and the record of history.

\section{The Literary Retro Movement in the Ming and Qing Dynasties Achieved Another Peak of Creation in Ancient Literary Classics.}

In the Ming and Qing dynasties, the retro movement was prosperous, which was due to that it has formed a kind of conservative style and innovative decline after more than a hundred years the development of ancient literature. However, the interweaving of ancient ways and reforms has brought about a new curtain on the creation of ancient literature in Ming and Qing dynasties. During 
this period, literatures think that they study prose in the two Han dynasties, study ancient poetry in Han Wei dynasties and study the articles in the tang dynasty. This retro reform has made the prose and the banal eight articles less and less and it is helpful for the further development of classical literature.

There was a great controversy in the Ming and Qing dynasties and appeared a new article style Ming and Qing novels. The composition of the classical view of literature has become more reasonable, During the Ming and Qing dynasties, the tang song faction had a positive significance in opposing the corrupt and backward eight articles, but there was no better innovation while actively suppressing the eight shares. They imitate the language and rhetoric of ancient literature deliberately, lacking spirituality in creation. Therefore, it was opposed by the public security faction of the late Ming dynasty. Yuan Hongdao has made the following criticism of the blind retro concept. "If in the Qin and Han dynasty, the writers would only imitate the ancients, then there would be no good articles in Qin and Han dynasty now." It shows that imitating the writing of the ancients does not reflect the value of contemporary literature.

\section{Conclusion}

To sum up, the formation and development of ancient Chinese literary classics are related to the literary era in certain historical periods. In the pre-Qin period, people attached great importance to classics. In the period of the Han and the Wei and Jin dynasties, the literary classics were formed. In the period of Sui and tang dynasties, song yuan, Ming and Qing dynasties, the classical view of ancient prose is constantly retro and innovative. We can see that the classical view of ancient literature is constantly changing. This gives new meaning to the study of ancient literature. The study of ancient literature helps us to understand the development of the ancient prose movement better, and to enlighten the study of literary theory in the later ages.

\section{References}

[1]. Li Jianwu. New exploration of "ancient Chinese literature" under the perspective of literary classics and modern ideology [J]. Journal of Neijiang normal university, 2013,32(07):91-97.

[2]. Wang Shili. The formation and evolution of the classical view of ancient literature [J]. Northern theory,2015, (01):13-16.

[3]. Gao Yan, Zhang Xianghua. A study of classic education and modern transformation in ancient Chinese literature [J]. Journal of Suihua college,2011,31(05):171-172.

[4]. Sato. A review of Xunzi in the 20th century -- a comparative review of the international perspective [J]. Journal of Handan college,2014,24(02):5-16.

[5]. Zhang Gang. A study on the propagation ecology of ancient literary classics [D]. Hubei institute of nationalities, 2016 .

[6]. Tang Liping. Reading classics, improving personality [D]. Hangzhou normal university,2006.

[7]. Kangzhen. Carry forward the tradition, innovate the discourse, and contribute wisdom -- the cultural responsibility of ancient Chinese literature research and the mission of The Times [J]. Literature review,2016(06):5-13.

[8]. Wang Songbao. Wei Yan Fa Yi. Wuzi [M]. Beijing: Zhonghua book bureau, 1987.Wang Xianghuan, Wang Xingxian. [9]. Wang Xianqian. The solution of Xun Zi Ji [M]. Beijing: zhonghua book bureau.2012.

[9]. Wang Xianghuan, Wang Xingxian. Wang Xianqian. Xunziji solution [M]. Beijing: Zhonghua book bureau.2012. Page 370 .

[10]. Chen Yanjie. Poetry. Note: volume [M], Beijing: people's literature publishing house, 1961. 